\title{
The effects of the Brazilian ant Dinoponera quadriceps venom on chemically induced seizure models
}

\author{
Kamila Soares Lopes ${ }^{a}$, Emiliano Ricardo Vasconcelos Rios ${ }^{b}$, Camila Nayane de Carvalho Lima ${ }^{\text {, }}$ \\ Maria Isabel Linhares ${ }^{b}$, Alba Fabíola Costa Torres ${ }^{\mathrm{a}}$, Alexandre Havt ${ }^{\mathrm{b}}$, Yves Patric Quinet ${ }^{\mathrm{c}}$, \\ Marta Maria de França Fonteles ${ }^{\mathrm{a}, \mathrm{b}}$, Alice Maria Costa Martins ${ }^{\mathrm{a}, \mathrm{b}, *}$ \\ ${ }^{a}$ Department of Clinical and Toxicological Analysis, Faculty of Pharmacy, Federal University of Ceara, Fortaleza, Ceara, Brazil \\ ${ }^{\mathrm{b}}$ Department of Physiology and Pharmacology, Faculty of Medicine, Federal University of Ceara, Fortaleza, Ceara, Brazil \\ ${ }^{\mathrm{c}}$ Laboratory of Entomology, State University of Ceara, Fortaleza, Ceara, Brazil
}

\section{A R T I C L E I N F O}

Article history:

Received 7 January 2013

Received in revised form 29 May 2013

Accepted 1 June 2013

Available online 7 June 2013

\section{Keywords:}

Dinoponera quadriceps venom

Ant

Seizure

\begin{abstract}
A B S T R A C T
Arthropod venoms are potential sources of neuroactive substances, providing new tools for the design of drugs. The aim of this study was to evaluate the effects of Dinoponera quadriceps venom (DqV) on seizure models in mice induced by pentylenetetrazole (PTZ), pilocarpine, and strychnine. In the PTZ model, intraperitoneal treatment with $\mathrm{DqV}(0.5 \mathrm{mg} / \mathrm{kg})$ increased the time until the first seizure and the percentage of survival $(155.4 \pm 27.7 \mathrm{~s} / 12.5 \%, p<0.05)$ compared to the control group $(79.75 \pm 3.97 \mathrm{~s} / 0 \%$ ), whereas endovenous treatment $(0.1 \mathrm{and} 0.5 \mathrm{mg} / \mathrm{kg})$ decreased the time until the first seizure $(0.1 \mathrm{mg} / \mathrm{kg}: 77.83 \pm 5.3 \mathrm{~s}$ versus $101.0 \pm 3.3 \mathrm{~s}$ in the control group; $0.5 \mathrm{mg} / \mathrm{kg}$ : $74.43 \pm 3.9 \mathrm{~s}$ versus $101.0 \pm 3.3 \mathrm{~s}$ for the control group, $p<0.05$ ). We did not observe significant changes in the pilocarpine- and strychnine-induced seizure models. In assays that measured oxidative parameters in the PTZ model, intraperitoneal treatment with $\mathrm{DqV}(0.5$ and $2.0 \mathrm{mg} / \mathrm{kg})$ only decreased the levels of MDA and nitrite in the cortex. However, endovenous treatment with DqV $(0.1$ and $0.5 \mathrm{mg} / \mathrm{kg})$ increased the levels of MDA in the cortex and hippocampus and at a dose of $0.5 \mathrm{mg} / \mathrm{kg}$ in the striatum. Moreover, increased in nitrite content was observed in all three of the brain regions analyzed. Taken together, the $D$. quadriceps venom caused both neuroprotective and neurotoxic effects in a PTZ-induced seizure model, and this effect was dependent on the route of administration used.
\end{abstract}

(c) 2013 Elsevier Ltd. All rights reserved.

\section{Introduction}

Epilepsy affects approximately 50 million people worldwide (Kramer and Cash, 2012) and is defined as a chronic disorder of the brain that is characterized by spontaneous and recurrent seizure activity, which is triggered by the abnormal discharge of neurons (Löscher, 1998; Tunnicliff, 1996). Treatment of this neurological disorder deserves special attention. Although anticonvulsant drugs have proven their efficacy, their use has demonstrated considerable side-effects. Furthermore, patients suffer from intractable conditions related to the type of crisis, drug resistance or other factors. Thus, there is a need for the development of new alternative therapeutic tools.

Animal venoms are sources of bioactive substances with biotechnological potential (Escoubas and King, 2009; Magalhães

\footnotetext{
* Corresponding author. Address: Department of Clinical and Toxicological Analysis, Faculty of Pharmacy, Federal University of Ceara. Rua Cap. Francisco Pedro, 1210, Rodolfo Teófilo, CEP: 60430-170, Fortaleza, Ceara, Brazil. Tel.: +55 85 3366 8269; fax: +55 8533668262.

E-mail address: martinsalice@gmail.com (A.M.C. Martins).
}

et al., 2007; Sanchez and Swenson, 2007). Their active molecules have structures with broad chemical diversity, biochemical specificity, and other molecular properties, that make them favorable as substances that lead to discovery of new drugs (Altmann, 2001; Clardy and Walsh, 2004). Brazil exhibits great biological diversity due to its varied climatic and geographical features, presenting a broad field for the study of products derived from its fauna and flora.

Previously, a variety of toxins derived from arthropods were isolated and purified and have been shown to be a source of neuroactive substances (Beleboni et al., 2004; Oliveira et al., 2005; Pizzo et al., 2000). The venom of the species of the Hymenoptera order (wasp, bees and ants) consists of a complex mixture of proteins, peptides and other compounds (Santos et al., 2011) that act on ion channels and receptors or that function via neurotransmitter release (Carneiro et al., 2003; Pizzo et al., 2004; Yokota et al., 2001). These properties provide new tools for the therapeutic design of novel drugs.

The Dinoponera quadriceps ant (Hymenoptera, Formicidae) is distributed in northeastern Brazil. Paiva and Brandão, 1995. Until 
the present moment, the biological effects of $D$. quadriceps venom (DqV) are poorly known and exist only one study demonstrating their antinociceptive property (Souza et al., 2012). In respect to studies on the central nervous system, the wasps are the best studied species of Hymenoptera order. Cunha et al. (2005) observed that the denatured venom of the wasp Polybia ignobilis exhibits anticonvulsant activity in some animal models and contains components that are capable of interacting with GABA and glutamate receptors in synaptosomes in the rat cortex. Furthermore, other venom of Hymenoptera order, extracted from the social wasp Polybia occidentalis also deserves particular attention due to its activity in experimental seizure models. It has been shown to block seizures that have been chemically induced by bicuculline, picrotoxin and kainic acid (Mortari et al., 2007).

The aim of this present study was to evaluate the effect of DqV on chemically induced seizure models.

\section{Materials and methods}

\subsection{Dinoponera quadriceps venom}

Ant colonies were collected (IBAMA authorization No. 28794-1) in "Serra de Maranguape" in Ceara State in Northeastern Brazil. The ants were maintained at the Laboratory of Entomology at the State University of Ceara. The venom was extracted using a capillary tube and was lyophilized and maintained at $-20^{\circ} \mathrm{C}$ until further use (Souza et al., 2012).

\subsection{Animals}

Male Swiss mice (28-33 g) were maintained at $27 \pm 2{ }^{\circ} \mathrm{C}$ under a 12/12 h light/dark cycle. Food and water were provided ad libitum. These animals were used in the chemically induced seizure models. This study was submitted and approved by the Ethics Committee on Animal Research of the Federal University of Ceara (No. 43/2011).

\subsection{Drugs}

All of the drugs were purchased from Sigma Chemical Co., USA. The lyophilized DqV was diluted in phosphate-buffered saline (PBS) and prepared for administration immediately prior to each experimental assay.

\subsection{Models of chemically induced seizures and behavioral assessment}

Male Swiss mice were pretreated with $\mathrm{DqV}$ ( 0.5 or $2.0 \mathrm{mg} / \mathrm{kg}$; $n=6-8$, i.p.) or $(0.1$ or $0.5 \mathrm{mg} / \mathrm{kg}, n=6-8$, e.v). Thirty or ten minutes after the i.p or e.v. administration, respectively, the seizures were induced in the animals using pentylenetetrazole (PTZ) $(80 \mathrm{mg} / \mathrm{kg}$, i.p.), pilocarpine (PILO) $(400 \mathrm{mg} / \mathrm{kg}$, i.p.) or strychnine (STRC) (3.0 mg/kg, i.p.) (Aprison et al., 1987; Turski et al., 1983; Yilmaz et al., 2007). The animals were placed in individual cages and were observed for 30 or $60 \mathrm{~min}$ to assess the following behavioural parameters (in seconds): latency to first seizure (elapsed time before the first seizure), latency to death (elapsed time until the death) and survival (number of dead animals). The seizure event was characterized primarily by hindlimb extension and/or uncoordinated jump (Turski et al., 1983; Aguiar et al., 2012). In the control group for each seizure model, the animals were pretreated with vehicle only (PBS).

\subsection{Measurement of oxidative stress parameters}

The oxidative stress parameters were evaluated in the PTZ-induced animal models because was only which showed significant results on the behavioral assessment tests. Three brain areas (prefrontal cortex, hippocampus and striatum) were dissected after behavioral assessment and were homogenized at $10 \%$ in sodium phosphate buffer to determine the degree of lipid peroxidation.

\subsubsection{Determination of lipid peroxidation levels}

Lipid peroxide formation was analyzed by measuring thiobarbituric acid reactive substances (TBARS), such as the levels of malondialdehyde (MDA). As previously described by Huong et al. (1998), the homogenates were mixed with $35 \%$ perchloric acid and centrifuged. After, $1.2 \%$ thiobarbituric acid was added to the supernatants, and the samples were then heated in a boiling water bath at $95^{\circ} \mathrm{C}$ for $30 \mathrm{~min}$. Finally, the MDA levels were determined spectrophotometrically at an absorbance of $535 \mathrm{~nm}$. In addition, these same brain areas were dissected in animals that were treated with vehicle only (PBS), in the absence of a seizure drug inducer (basal level group). Previously, a standard MDA curve was generated using concentrations of $50,25,12.5,6.25,3.12,1.56,0.78$, $0.39,0.195$ and $0.97 \mu \mathrm{g} / \mathrm{mL}$.

\subsubsection{Determination of the nitrite content}

The concentration of nitrite was measured as previously described by Green et al. (1981). Griess reagent was added to a 96well plate together with the supernatants of homogenates. Its absorbance was measured using a microplate reader at $560 \mathrm{~nm}$. In addition, the same brain areas in the animals treated with vehicle only (PBS) were dissected in the absence of a seizure drug inducer (basal level group). Previously, a standard curve of nitrite was generated using concentrations of $100,50,25,12.5,6.25,3.12$ and $1.56 \mathrm{nmol} / \mathrm{mL}$.

\subsection{Statistical analysis}

The data were expressed as the mean \pm SEM. For the statistical analysis of the first seizure latency and the mean time of death, a one-way analysis of variance (ANOVA) was performed followed by a Student Newman-Keuls post hoc test. Probability (P) values less than 0.05 were considered significant. A statistical evaluation of the survival curve using the Logrank (Mantel-Cox) test was separately performed with comparisons of the drugs curves vs. control curves.

\section{Results}

\subsection{Effects of the Dinoponera quadriceps venom on chemically induced seizures and behavioral assessment}

In the behavioral analysis, pretreatment with $\mathrm{DqV}(0.5 \mathrm{mg} / \mathrm{kg}$; i.p.) in a PTZ-induced seizure model significantly increased the time until the first seizure and the survival percentage (Table 1). No significant alterations in the pilocarpine- and strychnine-induced models were observed (Table 1 ).

When the mice were pretreated with $\mathrm{DqV}(0.1$ and $0.5 \mathrm{mg} / \mathrm{kg}$; e.v.) in the PTZ-induced seizure model, there was a significant reduction in the time until the first seizure (Table 2 ). No significant changes in the survival percentage and time until death in the PTZinduced, pilocarpine-induced and strychnine-induced seizure models were observed (Table 2). 
Table 1

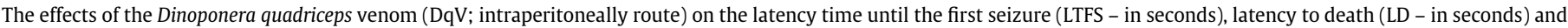
survival percentage $(S)$ in seizure models induced by pentylenetetrazole, pilocarpine and strychnine.

\begin{tabular}{|c|c|c|c|c|c|c|c|c|c|}
\hline \multirow[t]{2}{*}{ Treatments groups } & \multicolumn{3}{|c|}{ Pentylenetetrazole } & \multicolumn{3}{|l|}{ Pilocarpine } & \multicolumn{3}{|l|}{ Strychnine } \\
\hline & LTFS & LD & $\mathrm{S}(\%)$ & LTFS & LD & $\mathrm{S}(\%)$ & LTFS & LD & $\mathrm{S}(\%)$ \\
\hline Vehicle & $79.75 \pm 3,97$ & $307.4 \pm 36.52$ & 0 & $478.4 \pm 29.61$ & $603.1 \pm 28.73$ & 0 & $163.7 \pm 11.09$ & $197.1 \pm 28.2$ & 0 \\
\hline $\mathrm{DqV} 0.5 \mathrm{mg} / \mathrm{kg}$ & $155.4 \pm 27.7^{*}$ & $444.3 \pm 82.47$ & $12.5^{\#}$ & $464.4 \pm 24.39$ & $539.4 \pm 32.24$ & 0 & $156.3 \pm 26.86$ & $219.6 \pm 43.21$ & 0 \\
\hline $\mathrm{DqV} 2.0 \mathrm{mg} / \mathrm{kg}$ & $107.2 \pm 11.35$ & $446.7 \pm 139.5$ & 0 & $444.6 \pm 51.05$ & $487.4 \pm 56.96$ & 0 & $174.8 \pm 29.9$ & $344.9 \pm 56.13$ & 0 \\
\hline
\end{tabular}

The values are expressed as the mean \pm SEM in 6-8 mice.

* $p<0.05$ compared to the vehicle control group (one-way ANOVA followed by Newman-Keul's test).

\# $p<0.05$ compared to the survival curve of the vehicle control group (Logrank (Mantel-Cox) test).

Table 2

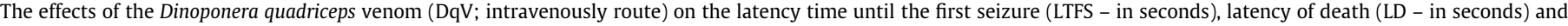
survival percentage $(S)$ in seizure models induced by pentylenetetrazole, pilocarpine and strychnine.

\begin{tabular}{|c|c|c|c|c|c|c|c|c|c|}
\hline \multirow[t]{2}{*}{ Treatments groups } & \multicolumn{3}{|c|}{ Pentylenetetrazole } & \multicolumn{3}{|l|}{ Pilocarpine } & \multicolumn{3}{|l|}{ Strychnine } \\
\hline & LTFS & LD & $\mathrm{S}(\%)$ & LTFS & LD & $\mathrm{S}(\%)$ & LTFS & LD & S (\%) \\
\hline Vehicle & $101.0 \pm 3.31$ & $306.9 \pm 43.77$ & 0 & $422.8 \pm 56.86$ & $498.3 \pm 73.67$ & 0 & $129.1 \pm 6.48$ & $150.6 \pm 5.84$ & 0 \\
\hline $\mathrm{DqV} 0.1 \mathrm{mg} / \mathrm{kg}$ & $77.83 \pm 5.27^{*}$ & $237.3 \pm 36.82$ & 0 & $410.0 \pm 22.44$ & $432.4 \pm 22.22$ & 0 & $121.1 \pm 12.44$ & $170.4 \pm 18.05$ & 0 \\
\hline DqV $0.5 \mathrm{mg} / \mathrm{kg}$ & $74.43 \pm 3.94^{*}$ & $267.1 \pm 39.11$ & 0 & $401.8 \pm 19.27$ & $424.9 \pm 19.39$ & 0 & $114.9 \pm 6.69$ & $169.5 \pm 23.77$ & 0 \\
\hline
\end{tabular}

The values are expressed as the mean \pm SEM in 6-8 mice.

" $p<0.05$ compared to the vehicle control group (one-way ANOVA followed by Newman-Keul's test).
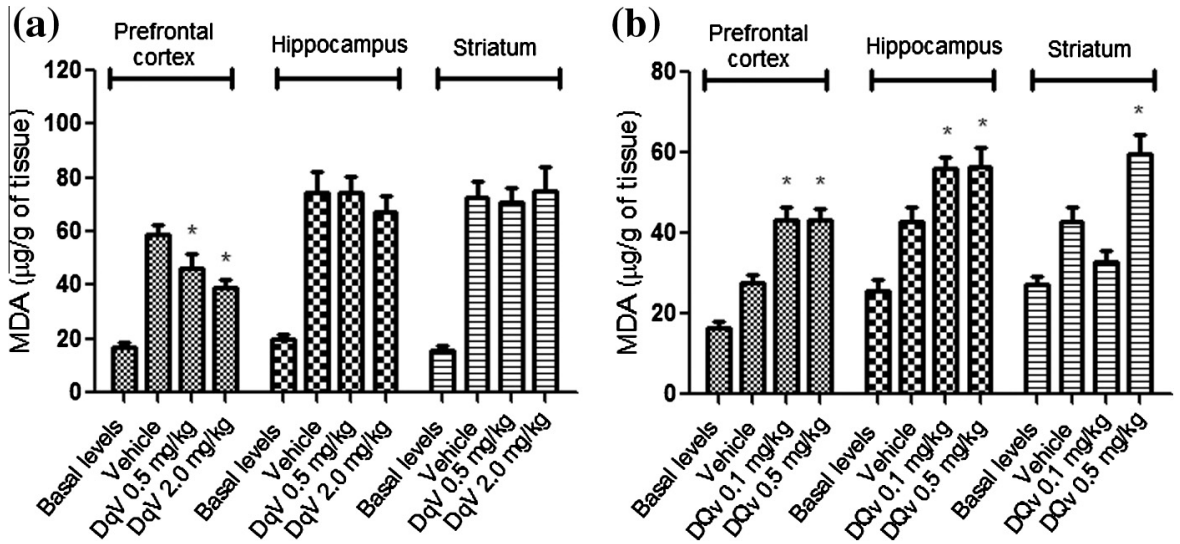

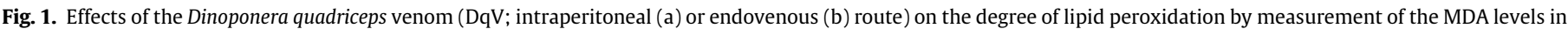
the pentylenetetrazole-induced seizure model. These results are expressed as the means \pm SEM. ${ }^{*} p<0.05$ compared to the vehicle group.

(a)

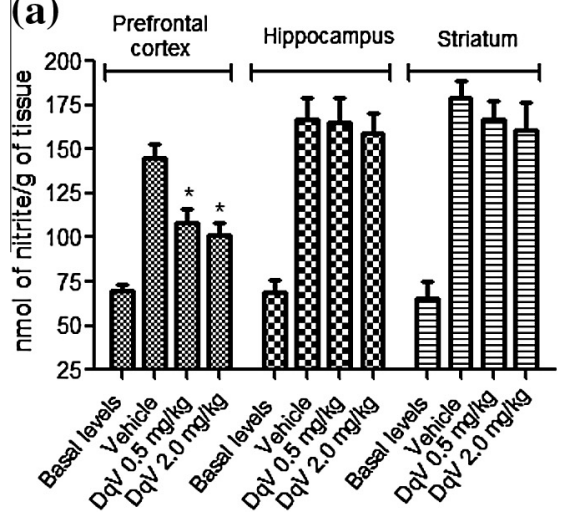

(b)

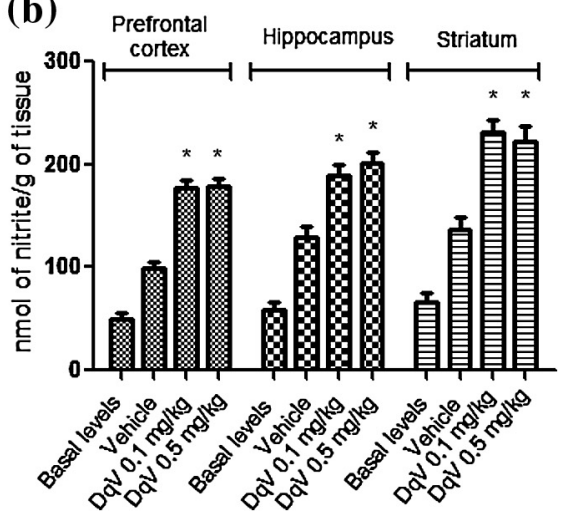

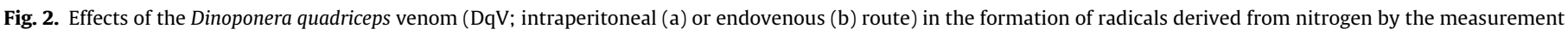
of the nitrite content in the pentylenetetrazole-induced seizure model. These results are expressed as the means \pm SEM. ${ }^{*} p<0.05$ compared to the vehicle group. 


\subsection{Effects on the measurement of oxidative stress parameters}

Measurement of oxidative stress parameters was performed only in model PTZ induced seizure assay after to observe changes in behavior assessment.

Pretreatment with $\mathrm{DqV}$ (0.5 and $2.0 \mathrm{mg} / \mathrm{kg}$; i.p.) decreased the levels of MDA and nitrite content only in the prefrontal cortex of the mice (Figs. 1a and 2a, respectively).

Furthermore, endovenous pretreatment with $\mathrm{DqV}$ (0.1 and $0.5 \mathrm{mg} / \mathrm{kg}$ ) caused an increase in the levels of MDA in the prefrontal cortex and hippocampus, and DqV at a dose of $0.5 \mathrm{mg} / \mathrm{kg}$ increased the levels of MDA in the striatum area (Fig. 1b). Moreover, it was observed an increase in the nitrite content in the prefrontal cortex, hippocampal and striatal areas (Fig. 2b).

\section{Discussion}

Several experimental animal models have been used in pharmacological screenings to identify anticonvulsant drugs. It was used in this study PTZ, pilocarpine and strychnine-induced seizure models. PTZ is a non-competitive antagonist of $\mathrm{GABA}_{\mathrm{A}}$ receptors, which act closing $\mathrm{Cl}^{-}$channels, thereby reducing the inhibitory neurotransmission mediated by GABA (Qu et al., 2005; Silva et al., 1998). The blockade of the onset of seizures induced by pilocarpine may be achieved by anti-cholinergic drugs, suggesting that activation of the muscarinic cholinergic receptor contributes to the initiation of seizures (Freitas and Tomé, 2010). Strychnine acts as a competitive antagonist of glycine, which reduces the inhibitory effects on the central nervous system (Kaputlu and Uzbay, 1997).

In our assessment of the effects of DqV in chemically induced seizure models, we observed significant alterations in both behavioral assessment assays and in the measurement of oxidative stress parameters in a PTZ-induced seizure model, suggesting that the effects observed with DqV are probably unrelated to the cholinergic or glycinergic pathways and may interfere with the PTZ binding site, thereby affecting the modulation of chloride channels in $\mathrm{GABA}_{\mathrm{A}}$ receptors. About this fact, has been reported that ant venom of the same genera, Dinoponera australis contains modifiers of ion channels (Hoffman, 2010; Johnson et al., 2010).

Interestingly, opposing effects of DqV activity were observed when animals received the drug via i.p. administration versus e.v. administration. We found that i.p. pretreatment with DqV resulted in neuroprotective effects because the administration of venom increased the time until the first seizure and reduced the oxidative stress parameters (the degree of lipid peroxidation and the nitrite content). Conversely, e.v. pretreatment caused neurotoxic effects, as demonstrated by the reduction in the time until the first seizure and an increase in the oxidative parameters analyzed. Thus, the venom probably acts by route-dependent modulating the $\mathrm{GABA}_{\mathrm{A}}$ receptor.

On the basis of these data, we suggested that DqV may contain both neuroprotective and neurotoxic components which act in favor of inhibitory neurotransmission as well as in the reduction of this type of neurotransmission. Studies show that the venom of other species of order Hymenoptera, the social wasp Agelaia vicina, contains two peptides, AvTx 7 and AvTx 8, which act on both excitatory and inhibitory neurotransmission (Oliveira et al., 2005; Pizzo et al., 2004).

These opposing effects also may be related to the presence of high molecular weight components in the venom. These molecules probably were presents in the blood circulation of the animal when DqV was injected e.v., but absent when this venom was administered via i.p. It was observed in other work that presence of high molecular weight components may be related with deleterious effects in CNS, as showed by Cunha et al. (2005) that the denatured venom of the $P$. ignobilis wasp produced anticonvulsant effects compared with the toxic effects in the total venom. With this, we can suggest that the neurotoxicity of DqV might be related to some macromolecular components.

Enzymatic activation or inactivation may also be considered as other hypothesis explaining to the opposing effects of DqV caused by these two administration routes. When DqV was injected e.v., enzymatic inactivation of a neuroprotective component may have occurred. Alternatively, in the absence of the inactivation of these components, the neurotoxic components may be primed and present at sufficient concentrations to exert harmful effects. However, this did not occur when the DqV was administered by intraperitoneal route.

Other important event involved in convulsive processes is the occurrence of oxidative stress (Ashrafi et al., 2007; Migliore et al., 2005; Perry et al., 2002). Lipid peroxidation has been reported to contribute to the deficient function of the lipid membrane during epileptogenesis, and the determination of MDA levels can be used as a marker of this event. Metabolites of nitric oxide (NO) have been implicated in the development of oxygen toxicity in the CNS. Increase in the extracellular concentration of NO is closely related to an increase in the cerebral blood flow, which precedes the appearance of electrical discharges (Demchenko et al., 2001; Sato et al., 2001), moreover NO can react with superoxide radicals forming peroxynitrite, which is a potent inducer of cell death.

The antioxidant agents may be a useful tool for attenuating the oxidative damage involved in seizure events. The measurement of the oxidative stress parameters suggest that the DqV may contain molecules that can positively or negatively interfere with the cellular oxidant/antioxidant mechanisms involved in a PTZ-induced seizure.

Interestingly, while neuroprotective effects were only observed in the prefrontal cortex in mice, neurotoxic effects occurred in three of the analyzed brain areas. Thus, a possible component with antioxidants properties may have an affinity for a specific brain structure, which is only present in the prefrontal cortex.

In conclusion, DqV caused both neuroprotective and neurotoxic effects in a PTZ-induced seizures model, and these effects were dependent on the route of drug administration. These findings contribute to the expansion of knowledge of the biological effects of the $D$. quadriceps ant venom. The results presented in this study are the first demonstration of the effect of $\mathrm{DqV}$ in seizures animal models.

\section{Acknowledgments}

We thank the Conselho Nacional de Desenvolvimento Científico e Tecnológico (CNPq), Fundação Cearense de Apoio ao Desenvolvimento Científico e Tecnológico (FUNCAP), and Coordenação de Aperfeiçoamento de Pessoal de Nível Superior (CAPES) for financial support.

\section{References}

Aguiar, C.C.T. Almeida, A.B. Araújo, P.V.P. Vasconcelos, G.S., Chaves, E.M.C. do Vale, O.C., Macêdo, D.S., de Sousa, F.C.F., Viana, G.S.B., Vasconcelos, S.M.M., 2012 Anticonvulsant effects of agomelatine in mice. Epilepsy Behav. 24, 324-328.

Altmann, K.H., 2001. Microtubule-stabilizing agents: a growing class of important anticancer drugs. Curr. Opin. Chem. Biol. 5, 424-431.

Aprison, M.H., Lipkowitz, K.B., Simon, J.R., 1987. Identification of a glycine-like fragment on the strychnine molecule. J. Neurosci. Res. 17 (3), 209-213.

Ashrafi, M.R., Shams, S., Nouri, M., Mohseni, M., Shabanian, R., Yekaninejad, M.S Chegini, N., Khodadad, A., Safaralizadeh, R., 2007. A probable causative factor for an old problem: selenium and glutathione peroxidase appear to play important roles in epilepsy pathogenesis. Epilepsia 48, 1750-1755.

Beleboni, R.O., Pizzo, A.B., Fontana, A.C.K., Carolino, R.O.G., Coutinho-Netto, J. Santos, W.F., 2004. Spider and wasp neurotoxins: pharmacological and biochemical aspects. Eur. J. Pharmacol. 493, 1-17. 
Carneiro, A.M.D., Kushmerick, C., Koenen, J., Arndt, M.H.L., Cordeiro, M.N., ChavezOlortegui, C., Diniz, C.R., Gomez, M.V., Kalapothakis, E., Prado, V.F., 2003. Expression of a functional recombinant Phoneutria nigriventer toxin active on $\mathrm{K}+$ channels. Toxicon 41, 305-313.

Clardy, J., Walsh, C., 2004. Lessons from natural molecules. Nature 432, 829-837.

Cunha, A.O., Mortari, M.R., Oliveira, L., Carolino, R.O., Coutinho-Netto, J., Dos Santos, W.F., 2005. Anticonvulsant effects of the wasp Polybia ignobilis venom on chemically induced seizures and action on GABA and glutamate receptors. Comp. Biochem. Physiol. C Toxicol. Pharmacol. 141(c), 50-57.

Demchenko, I.T., Boso, A.E., Whorton, A.R., Piantadosi, C.A., 2001. Nitric oxide production is enhanced in rat brain before oxygen-induced convulsions. Brain Res. 917, 253-261.

Escoubas, P., King, G.F., 2009. Venomics as a drug discovery platform. Expert Rev. Proteomics 6 (3), 221-224.

Freitas, R.M., Tomé, A.R., 2010. Ações neuroprotetoras da vitamina C no corpo estriado de ratos após convulsões induzidas pela pilocarpina. Rev. Psiq. Clín. 37, 105-108.

Green, L.C., Tannenbaum, S.R., Goldman, P., 1981. Nitrate synthesis in the germfree and conventional rat. Science 212, 56-58.

Hoffman, D.R., 2010. Ant venoms. Curr. Opin. Allergy Clin. Immunol. 10, 342-346.

Huong, N.T., Matsumoto, K., Kasa, R., Yamasaki, K., Watanebe, H., 1998. In vitro antioxidant activity of vietnamese ginseng saponin and its components. Biol. Pharm. Bull. 21, 978-981.

Johnson, S.R., Copello, J.A., Evans, M.S., Suarez, A.V., 2010. A biochemical characterization of the major peptides from the venom of the giant neotropical hunting ant Dinoponera australis. Toxicon 55, 702-710.

Kaputlu, I., Uzbay, T., 1997. L-NAME inhibits pentylenetetrazole and strychnineinduced seizures in mice. Brain Res. 753, 98-101.

Kramer, M.A., Cash, S.S., 2012. Epilepsy as a disorder of cortical Network Organization. Neuroscientist 18 (4), 360-372.

Löscher, W., 1998. New visions in the pharmacology of anticonvulsion. Eur. J. Pharmacol. 342, 1-13.

Magalhães, A., Magalhães, H.P., Richardson, M., Gontijo, S., Ferreira, R.N., Almeida A.P., Sanchez, E.F., 2007. Purification and properties of a coagulant thrombinlike enzyme from the venom of Bothrops leucurus. Comp. Biochem. Physiol. A Mol. Integr. Physiol. 146 (4), 565-575.

Migliore, L., Fontana, I., Colognato, R., Coppedè, F., Siciliano, G., Murri, L., 2005. Searching for the role and the most suitable biomarkers of oxidative stress in Alzheimer's disease and in other neurodegenerative diseases. Neurobiol. Aging 26, 587-595.

Mortari, M.R., Cunha, A.O., de Oliveira, L., Vieira, E.B., Gelfuso, E.A., Coutinho-Netto, J., Ferreira dos Santos, W., 2007. Anticonvulsant and behavioural effects of the denatured venom of the social wasp Polybia occidentalis (Polistinae, Vespidae). Basic Clin. Pharmacol. Toxicol. 97, 289-295.

Oliveira, L., Cunha, A.O.S., Mortari, M.R., Pizzo, A.B., Miranda, A., Coimbra, N.C., Dos Santos, W.F., 2005. Effects of microinjections of neurotoxin AvTx8, isolated from the social wasp Agelaia vicina (Hymenoptera, Vespidae) venom, on GABAergic nigrotectal pathways. Brain Res. 103, 74-81.

Paiva, R.V.S., Brandão, C.R.F., 1995. Nests, worker population, and reproductive status of workers, in the giant queenless ponerine ant Dinoponera Roger (Hymenoptera: Formicidae). Ethol. Ecol. Evol. 7, 297-312.

Perry, G., Nunomura, A., Hirai, K., Zhu, X., Perez, M., Avila, J., Castellani, R.J., Atwood, C.S., Aliev, G., Sayre, L.M., Takeda, A., Smith, M.A., 2002. Is oxidative damage the fundamental pathogenic mechanism of Alzheimer's and other neurodegenerative disease? Free Radical Biol. Med. 33, 1475-1479.

Pizzo, A.B., Beleboni, R.O., Fontana, A.C.K., Ribeiro, A.M., Miranda, A., CountinhoNetto, J., dos Santos, W.F., 2004. Characterization of the actions of AvTx7 isolated from Agelaia vicina (Hymenoptera: Vespidae) wasp venom on synaptosomal glutamate uptake and release. J. Biochem. Mol. Toxicol. 18, 6168.

Pizzo, A.B., Fontana, A.C.K., Coutinho-Netto, J., Santos, W.F., 2000. Effects of the crude venom of the social wasp Agelaia vicina on gaminobutyric acid and glutamate uptake in synaptosomes from rat cerebral cortex. J. Biochem. Mol. Toxicol. 14, 88-94.

Qu, H., Eloqayli, H., Sonnewald, U., 2005. Pentylenetetrazole affects metabolism of astrocytes in culture. J. Neurosci. Res. 79, 48-54.

Sanchez, E.F., Swenson, S., 2007. Proteases from south american snake venoms affecting fibrinolysis. Curr. Pharm. Anal. 3 (2), 147-157.

Santos, L.D., Pieroni, M., Menegasso, A.R.S., Pinto, J.R.A.S., Palma, M.S., 2011. A new scenario of bioprospecting of Hymenoptera venoms through proteomic approach. J. Venom Anim. Toxins Incl. Trop. Dis. 17 (4), 364-377.

Sato, T., Takeda, Y., Hagioka, S., Zhang, S., Hirakawa, M., 2001. Changes innitric oxide production and cerebral blood flow before development of hyperbaric oxygeninduced seizures in rats. Brain Res. 918, 131-140.

Silva, L.F., Pereira, P., Elisabetsky, E., 1998. A neuropharmacological analysis of PTZinduced kindling in mice. Gen. Pharmac. 31, 47-50.

Souza, P.L., Quinet, Y., Ponte, E.L., Vale, J.F., Torres, A.F.C., Pereira, M.G., Assreuy, A.M.S., 2012. Venom's antinociceptive property in the primitive ant Dinoponera quadriceps. J. Ethnopharmacol. 144 (1), 213-216.

Tunnicliff, G., 1996. Basis of the antiseizure action of phenytoin. Gen. Pharmacol. 27 (7), 1091-1097.

Turski, W.A., Cavalheiro, E.A., Schwartz, M., Czuczwar, S.J., Kleinrok, Z., Turski, L., 1983. Limbic seizures produced by pilocarpine in rats: behavioural, electroencephalographic and neuropathological study. Behav. Brain Res. 9, 315-335.

Yilmaz, I., Sezer, Z., Kayir, H., Uzbay, T.I., 2007. Mirtazapine does not affect pentylenetetrazole- and maximal electroconvulsive shock-induced seizures in mice. Epilepsy Behav. 11 (1), 1-5.

Yokota, H., Tsubokawa, H., Miyawaki, T., Konno, K., Nakayama, H., Masuzawa, T., Kawai, N., 2001. Modulation of synaptic trasnmission in hippocampal CA1 neurons by a novel neurotoxin (beta-pompilidotoxin) derived from wasp venom. Neurosci. Res. 41, 365-371. 